\title{
A Note on Artificial Pitches and Home Advantage in Dutch Professional Football
}

\author{
Jan C. van Ours ${ }^{1,2,3}$ \\ Published online: 5 February 2019 \\ () The Author(s) 2019
}

\begin{abstract}
In professional football there is an advantage of playing at home. In the Netherlands, in the Eredivisie, the top tier of professional football the majority of teams play their home matches on natural grass but there are also quite a few teams playing on an artificial pitch. Analyzing match data from the seasons 2014/15 to 2017/18, this paper finds that Eredivisie teams who play on an artificial pitch have an additional home advantage.
\end{abstract}

Keywords Professional football $\cdot$ Artificial pitch

JEL Classification Z21 $\cdot$ L83

\section{Introduction}

There is no dispute about the existence of a home advantage in professional football. In his seminal study on home advantage in English football, Pollard (1986) investigates developments in home advantage in the top league since its formation in 1888 up to 1984 concluding that this has not changed very much. Discussing a variety of potential causes of home advantage in professional football Pollard (1986) concludes that crowd size and travel fatigue do not seem to be important while for other

\footnotetext{
The author thanks Sanne Lin for very helpful research assistance and Lucas Besters, Ruud Koning, Martin van Tuijl, Thomas Peeters and Thijs Velema as well as participants of a sports economics seminar at University of Melbourne and an ECASE workshop at Erasmus School of Economics for critical but helpful remarks on previous versions of the paper.

Jan C. van Ours

vanours@ese.eur.nl

1 Erasmus School of Economics, Erasmus University Rotterdam, Erasmus Center for Applied Sports Economics (ECASE) and Tinbergen Institute Rotterdam, Rotterdam, The Netherlands

2 Department of Economics, University of Melbourne, Parkville, Australia

3 CEPR, London, UK
} 
potential causes such as familiarity with local conditions, referee bias and team tactics the effects are unclear.

Boyko et al. (2010) claim that home advantage in English Premiership football is influenced by crowd size and referee decisions in terms of penalties and yellow cards. For the highest German league, Buraimo et al. (2010) find that teams that play in stadiums with running tracks have a smaller referee bias which they attribute to a bigger distance between play and audience. Ponzo and Scoppa (2018) analyze same-stadium derbies across Europe, i.e. matches between teams that share the same stadium. This set-up rules out travel distance and familiarity with the stadium as determinants of the home advantage. Their main conclusion is that home advantage depends on the support of the crowd also because referee's decisions tend to be biased in favor of the home team.

In some leagues in professional football there are rules on the nature of the pitch where natural grass is the default but sometimes an artificial pitch is allowed. An artificial pitch is a surface of synthetic fibers which resembles natural grass because of its color but is sometime referred to as a 'plastic pitch'. In English professional football, four clubs had an artificial pitch for a while mainly during the 1980s. In 1995, the use of artificial pitches was banned from English professional football because of concern over long-term injuries and different ball dynamics, i.e. interactions between player and ball as well as between ball and surface that were different from those on a natural grass pitch. Since October 2016, artificial pitches are permitted in lower divisions in English football but still banned from the two top leagues.

There are several financial benefits related to an artificial pitch as compared to natural grass. Artificial pitches can be used more intensively thus allowing more activities including outsourcing for commercial activities. Furthermore, with an artificial pitch clubs are often no longer in need of additional training grounds while clubs with a natural grass pitch do need additional training grounds to avoid damage to the natural grass because of too intensive use. Artificial pitches are also thought to be weather-proof in the sense that unlike natural grass it can handle heavy rains, frost and the like. Therefore, training sessions do not need to be canceled and games do not need to be postponed anymore. If postponed, matches are rearranged to midweek nights attracting a smaller crowd and thus generating less income for the clubs.

Financial advantages in terms of higher revenues and lower costs are important, especially for clubs with limited financial means. Some Dutch clubs claim that using an artificial pitch reduces costs by about half a million Euro annually. Since at the bottom of the league the overall budget is in the range of 5 to 10 million Euro this cost reduction is substantial. Whereas an artificial pitch has clear financial advantages it is not very popular among players and coaches. There are at least three reasons for this ( Trombley (2016)). There is a perception of an artificial pitch increasing injury rates, being more tiring to play on and introducing a different behavior of the ball, which is thought to move faster and bounce higher than it does on natural grass. There is no evidence that playing on artificial grass increases injury rates [see, for example, Ekstrand et al. (2011) and Lanzetti et al. (2017)]. However, if players think there is an increased injury risk they may change their style of play thereby reducing their performance. An artificial pitch may be more tiring and it may introduce different ball dynamics, leading to a different playing style (Andersson et al. 
2008). A team playing on an artificial pitch may attract players who are more able to play on such a pitch, have more experience in dealing with the different ball dynamics or may be better in reducing injury risks. If so, these teams may have an additional home advantage compared to teams playing on natural grass.

One may wonder why in professional football, with a double round-robin competition home advantage is an issue at all. If every team plays the same number of matches home and away against the same opponents home advantages cancel. However, if an artificial pitch introduces an additional home advantage the effects no longer cancel. Whether or not an artificial pitch introduces an additional home advantage has rarely been investigated. Barnett and Hilditch (1993) investigate the four teams in English league football that for some seasons had an artificial pitch. The main conclusion is that there was indeed an additional home advantage related to an artificial pitch equivalent to 0.28 points and 0.31 goals per match. In the meantime, the quality of artificial grass has improved substantially and the question is, whether current professional football teams that play on an artificial pitch still have an additional home advantage. Trombley (2016), analyzing four seasons (2011 to 2014) of US Major League Soccer, suggests that this is not the case. However, Hvattum (2015) concludes from an analysis of Norwegian league football from 2001 to 2013 that teams playing on artificial turf have a greater home advantage of approximately 2.5 points over the season.

The current paper investigates, whether teams who play their home matches on an artificial pitch have an additional home advantage compared to teams who play their home matches on natural grass. To do this, I use data from four seasons of the top tier of Dutch professional football, the Eredivisie. The identification of the artificial grass effect is based on a simple strategy that takes into account that the difference in strength between two teams cancels out in pairs of matches.

The set-up of the paper is as follows. In Sect. 2, I provide a brief description of the top tier of Dutch professional football. In Sect. 3, I discuss how to establish home advantages. Section 4 presents the quantitative analysis and discusses the parameter estimates. Section 5 concludes.

\section{Dutch Professional Football}

The Dutch top tier of professional football has 18 teams each of which plays 17 home and 17 away matches. For a win a team gets three points, for a draw this is one and for a loss no points are given. The team that has the highest number of points after 34 matches wins the championship and has traditionally been entitled to play in the European Champions League the next season. The team with the lowest number of points is relegated and replaced by the winner of the second tier. Numbers 16 and 17 play post-competition matches against teams from the second tier to determine whether or not they will be relegated.

My analysis is based on match results from four seasons, 2014/15 to 2017/18. Whereas in earlier seasons only two teams had an artificial pitch from 2014/15 to 2016/17 there were six teams with an artificial pitch while in the last season of the analysis there were seven teams with such a pitch. Figure 1 gives an overview of the 
Fig. 1 Goals scored and goals conceded by team; end of season 2014/15 - 2017/18. Note: 72 observations ( 18 teams in 4 seasons); 14 teams were present in all seasons, 1 team in three seasons, 5 teams in two seasons and 3 teams in one season

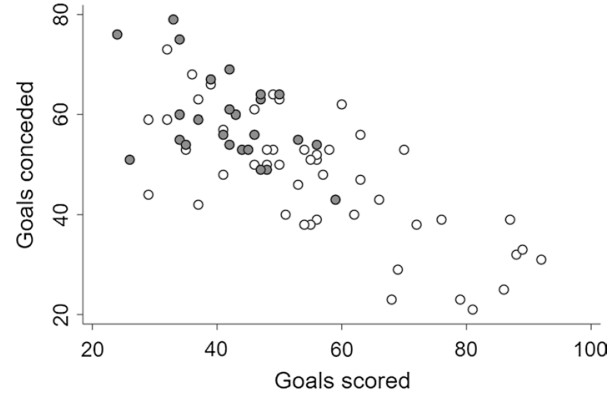

Teams with Natural Grass $\quad$ Teams with Artificial Pitch

Table 1 Goals and points by surface of the pitch; averages 2014/15-2017/18

\begin{tabular}{llllllll}
\hline & Goals home & Away & $\Delta$ & Points home & Away & $\Delta$ & Obs. \\
\hline Natural grass & 1.83 & 1.25 & 0.58 & 1.74 & 1.02 & 0.72 & 799 \\
Artificial pitch & 1.39 & 1.53 & -0.15 & 1.31 & 1.44 & -0.13 & 425 \\
All & 1.68 & 1.35 & 0.33 & 1.59 & 1.17 & 0.42 & 1224 \\
\hline
\end{tabular}

$\Delta$ difference, $O b s$. number of matches

number of goals scored and the number of goals conceded by the end of each season. There is a clear negative relationship between goals scored and goals conceded. The strongest teams are bottom-right, the weakest teams are top-left. The teams with a natural grass pitch are distributed over the whole range while the teams with an artificial pitch are predominantly top-left. This is no coincidence. Teams with a small budget are more likely to be weaker and for financial reasons are more likely to have an artificial pitch.

Table 1 provides a summary overview of goal scoring and points achieved distinguished by type of pitch. On average on natural grass, the home team scores 0.58 more goals than it concedes while it obtains 0.72 more points than the away team. These numbers do not represent the home advantage of playing on natural grass since these teams are on average stronger than teams that play on an artificial pitch. This is confirmed in the second row of Table 1 which indicates that on an artificial pitch home teams concede 0.15 more goals than they score with the visiting team obtaining 0.13 more points. The bottom row does present the average home advantage as this is based on all teams so differences in strength cancel. The average home advantage is equal to 0.33 goals and 0.42 points.

\section{Calculating Home Advantage}

Clarke and Norman (1995) present a simple method to determine the home advantage and the quality of each team participating in a particular season. In terms of goal difference, this works as follows (in terms of point difference it is similar). Ignoring random 
influences and ignoring for the moment an index for season, the result of a home match of team $i$ against team $j$, the goal difference $w_{i j}$, is determined by the difference in the quality of both teams, $q_{i}-q_{j}$ and the home advantage $h_{i}$ of team $i$ :

$$
w_{i j}=q_{i}-q_{j}+h_{i}
$$

Similarly, the goal difference of team $i$ playing away against team $j$ is defined as:

$$
w_{j i}=q_{i}-q_{j}-h_{j}
$$

Quality is normalized such that average quality over the teams is zero, while $H$ is defined as total home advantage aggregated over all teams:

$$
\sum_{i=1}^{N} q_{i}=0, H=\sum_{i=1}^{N} h_{i}
$$

where $N$ is the number of teams in the league. Over a season, team $i$ has a home goal difference $H G D_{i}$ that is equal to the sum over $N-1$ home matches. So:

$$
H G D_{i}=\sum_{j(j \neq i)}^{N} w_{i j}=(N-1) q_{i}-\sum_{j(j \neq i)}^{N} q_{j}+(N-1) h_{i}
$$

Since from equation (3) it holds that $\sum_{j(j \neq i)}^{N} q_{j}=-q_{i}$, equation (4) can be rewritten as:

$$
H G D_{i}=N q_{i}+(N-1) h_{i}
$$

Summing over the home goal differences of all teams and using the normalization that the average quality over all teams is equal to zero, leads to

$$
\sum_{i=1}^{N} H G D_{i}=\sum_{i=1}^{N}\left(N q_{i}+(N-1) h_{i}\right)=(N-1) \sum_{i=1}^{N} h_{i}=(N-1) H
$$

Therefore, $H$ can be calculated as

$$
H=\frac{\sum_{i=1}^{N} H G D_{i}}{N-1}
$$

Similarly, for the away goal difference of team $i$ it holds

$$
A G D_{i}=\sum_{j(j \neq i)}^{N} w_{j i}=(N-1) q_{i}-\sum_{j(j \neq i)}^{N} q_{j}-\sum_{j(j \neq i)}^{N} h_{j}
$$

Since $\sum_{j(j \neq i)}^{N} h_{j}=H-h_{i}$, equation (8) can be rewritten as:

$$
A G D_{i}=N q_{i}-H+h_{i}
$$

Subtracting equation (9) from equation (5): 
(a) Attendance and home advantage; goals (left) and points (right)
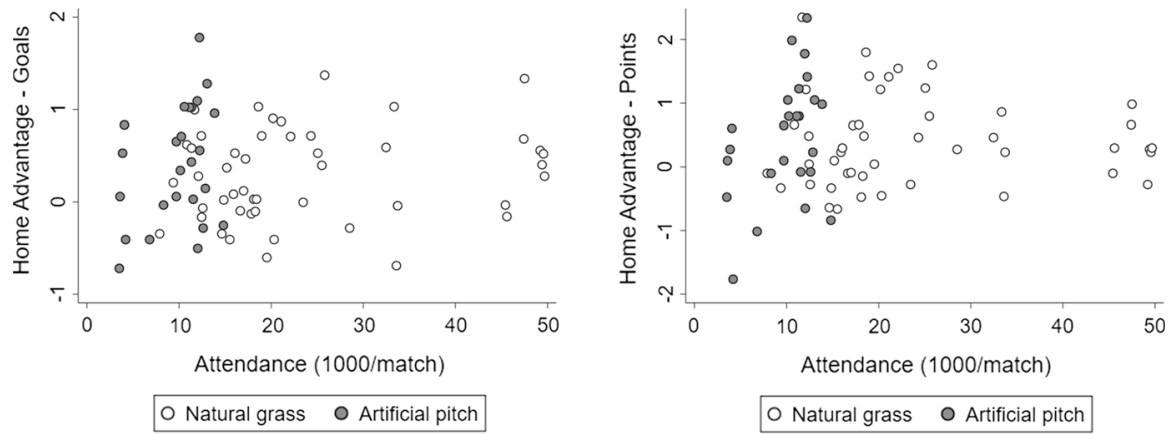

(b) Annual budget and quality; goals (left) and points (right)
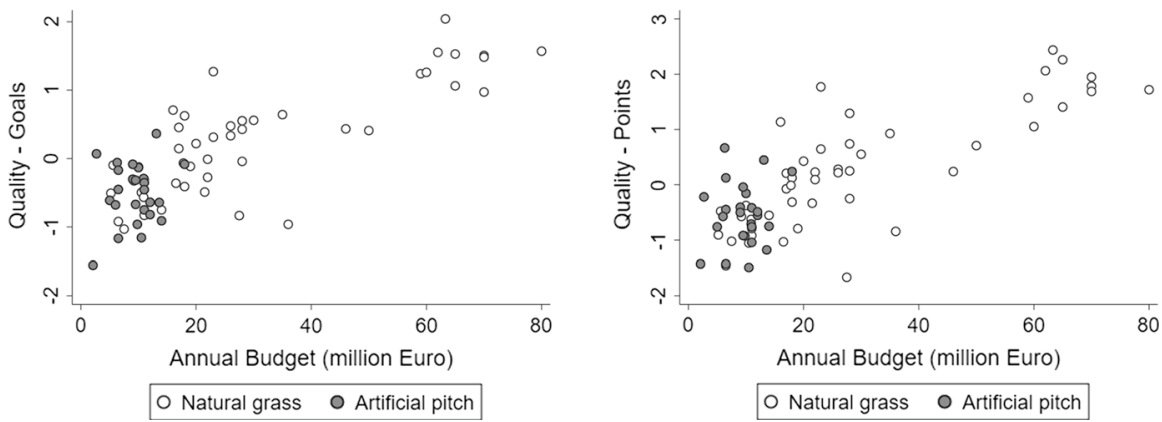

Fig. 2 Home advantage and quality per team; 2014/15-2017/18

$$
H G D_{i}-A G D_{i}=H+(N-2) h_{i}
$$

From this, the home advantage for team $i$ can be calculated as

$$
h_{i}=\frac{H G D_{i}-A G D_{i}-H}{N-2}
$$

Using equation (5) the quality of team $i$ can be calculated as

$$
q_{i}=\frac{H G D_{i}-(N-1) h_{i}}{N}
$$

Appendix provides a complete overview of the calculated home advantage and quality for every team in the four seasons of the analysis in terms of goals. Figure 2 presents some stylized relationships to get an idea about possible determinants of team-specific differences in home advantage and quality.

The top two graphs provide information about the home advantage, the bottom two about quality. The left-hand side graphs give the results in terms of goals, the right-hand side graphs do the same in terms of points. The range in home advantages is substantial, from -1 to almost +2 for goals and from -2 to +2 for 
Table 2 Home advantage by surface of the pitch; seasons 2014/15-2017/18

\begin{tabular}{lllrlrr}
\hline & $\begin{array}{l}\text { Goals natural } \\
\text { grass }\end{array}$ & Artificial pitch & \multicolumn{1}{l}{$\begin{array}{l}\text { Points natu- } \\
\text { ral grass }\end{array}$} & Artificial pitch & $\Delta$ \\
\hline $2014 / 15$ & 0.19 & 0.55 & 0.36 & 0.26 & 0.74 & 0.38 \\
$2015 / 16$ & 0.39 & 0.06 & -0.33 & 0.51 & 0.22 & -0.29 \\
$2016 / 17$ & 0.25 & 0.78 & 0.53 & 0.34 & 0.70 & 0.36 \\
$2017 / 18$ & 0.36 & 0.23 & -0.13 & 0.55 & 0.16 & -0.39 \\
Average & 0.30 & 0.41 & 0.11 & 0.41 & 0.46 & 0.05 \\
\hline
\end{tabular}

$\Delta$ difference

Table 3 Goals and points by type of match; averages 2014/15-2017/18

\begin{tabular}{llllllll}
\hline Pairs of pitches & Goals home & Away & $\Delta$ & Points home & Away & $\Delta$ & Obs. \\
\hline All & 1.68 & 1.35 & 0.33 & 1.59 & 1.17 & 0.42 & 612 \\
Same & 1.70 & 1.46 & 0.24 & 1.55 & 1.21 & 0.35 & 319 \\
Mixed & 1.65 & 1.22 & 0.43 & 1.63 & 1.13 & 0.51 & 293 \\
$2 \Delta(=A)$ & & & 0.39 & & & 0.32 & \\
\hline
\end{tabular}

$\Delta$ difference, $A$ extra advantage of having an artificial pitch, Obs. number of pairs of matches

points. There does not seem to be a relationship between home advantage and stadium attendance. Clubs with the largest stadium attendance do not have a higher home advantage than clubs with a much smaller stadium attendance.

The bottom graphs of Fig. 2 show that the calculated quality varies from -2 to +2 both for goals and points. There is a clear relationship between the annual budget of a team and the quality of that team. The relationship is not perfect but clearly the top three of the league have more quality than the bottom teams. Teams with an artificial pitch on average have a lower quality than teams with natural grass. Obviously, this is related to the difference in financial means which induced some clubs with a low budget to adopt an artificial pitch.

Table 2 presents a summary overview of home advantages in terms of goals and points distinguished by the surface of the pitch. On average over all seasons, the home advantage of an artificial pitch is only slightly larger than the home advantage of a natural grass pitch, 0.11 goals and 0.05 points. This way to obtain the additional home advantage of an artificial pitch would be comparable to earlier studies.

In the current paper, I follow a different strategy to establish the additional home advantage of having an artificial pitch. To illustrate my line of reasoning, Table 3 presents a summary overview of home goals and away goals according to whether both teams played on a different pitch or both teams played on the same pitch (both natural grass or both artificial pitch). The top row of Table 3 is identical to the bottom row of Table 1 since combining match pairs does not alter the calculation of the average home advantage; it is just the number of observations that is halved. 
For teams who both play on the same type of pitch, on average over the four seasons the home team scores 1.70 goals per match while the away team scores 1.46 goals. Since over all matches, the difference in the strength between two teams is equal, the goal difference of 0.24 can be attributed to the regular home advantage.

When teams with a different home ground play against each other, the results are different. Now, the home teams score of average 1.65 goals while the away teams score 1.22 goals. The difference of 0.43 can be attributed to the regular home advantage and half of the additional home advantage. From this, I conclude that the average additional home advantage of playing on an artificial pitch is equal to 0.39 goals. Similarly, the additional home advantage of playing on an artificial pitch is equal to 0.32 points.

\section{Quantitative Analysis}

\subsection{Statistical Model}

As Table 2 shows, the calculated home advantages at the level of individual teams are volatile over time. Therefore, the empirical analysis is focused on estimating the average home advantage and the average additional home advantage due to an artificial pitch. Although the strength of a team may vary because of injuries or suspensions of key players, I assume that the strength of a team is constant within a season. As long as the variation of strength within a season does not vary systematically with the nature of the pitch there is no bias in my parameter estimates. In the baseline estimates, I also assume that the additional home advantage of having an artificial pitch is time-invariant. My main assumption through which my approach is different from earlier studies is that teams with a natural grass home pitch suffer a disadvantage when playing on an artificial pitch while teams with an artificial pitch do not suffer a disadvantage when playing on natural grass.

For all matches played at home by team $i$ against opponent team $j$ in season $t$ it holds:

$$
w_{i j t}=q_{i t}-q_{j t}+h+d_{i}\left(1-d_{j}\right) A+\varepsilon_{i j t}
$$

where $w$ represents the indicator for the match results from the perspective of the home team, i.e. goal advantage or points advantage. Furthermore, $q_{i}$ represents the strength of team $i$ and $q_{j}$ represents the strength of team $j, h$ is the regular home advantage, $d_{i}$ and $d_{j}$ are a dummy variables indicating if team $i$ and $j$ play their home matches on natural grass, $A$ indicates the additional home advantage of playing on an artificial pitch and $\varepsilon_{i j t}$ is an error term.

Similarly, for team $j$ playing at home against team $i$ it holds:

$$
w_{j i t}=q_{j t}-q_{i t}+h+\left(1-d_{i}\right) d_{j} A+\varepsilon_{j i t}
$$

By taking the average of equations (13) and (14), the strengths of both teams cancel out and for every pair of $i$ and $j$ in season $t$ it holds:

$$
S_{i j t}=h+\left(\frac{d_{i}+d_{j}}{2}-d_{i} d_{j}\right) A+\epsilon_{i j t}
$$


Table 4 Parameter estimates equation (15)

\begin{tabular}{|c|c|c|c|c|c|c|c|c|c|}
\hline & \multicolumn{4}{|c|}{ Goals per match } & \multicolumn{4}{|c|}{ Points per match } & \multirow[b]{2}{*}{ Obs } \\
\hline & $h$ & & $A$ & & $h$ & & $A$ & & \\
\hline a. Baseline & 0.24 & $(0.07)^{* * *}$ & 0.39 & $(0.19)^{* *}$ & 0.35 & $(0.09)^{* * *}$ & 0.32 & $(0.26)$ & 612 \\
\hline b. Top 3 & 0.23 & $(0.11)^{* *}$ & 0.71 & $(0.34)^{* *}$ & 0.28 & $(0.13)^{* *}$ & 0.44 & $(0.37)$ & 192 \\
\hline Non-top 3 & 0.24 & $(0.09)^{* * *}$ & 0.28 & $(0.23)$ & 0.39 & $(0.13)^{* * *}$ & 0.25 & $(0.34)$ & 420 \\
\hline c. Panel & 0.31 & $(0.08)^{* * *}$ & 0.16 & $(0.24)$ & 0.44 & $(0.11)^{* * *}$ & 0.04 & $(0.34)$ & 364 \\
\hline Non-panel & 0.10 & $(0.12)$ & 0.75 & $(0.30)^{* *}$ & 0.18 & $(0.16)$ & 0.76 & $(0.41)^{*}$ & 248 \\
\hline d. Non-top 3 panel & 0.36 & $(0.12)^{* * *}$ & -0.12 & $(0.33)$ & 0.54 & $(0.17)^{* * *}$ & -0.25 & $(0.47)$ & 220 \\
\hline Others & 0.17 & $(0.08)^{* *}$ & 0.68 & $(0.23)^{* * *}$ & 0.25 & $(0.11)^{* *}$ & 0.63 & $(0.30)^{* *}$ & 392 \\
\hline e. No $2017 / 18$ & 0.21 & $(0.08)^{* * *}$ & 0.53 & $(0.21)^{* *}$ & 0.28 & $(0.10)^{* * *}$ & 0.63 & $(0.29)^{* *}$ & 459 \\
\hline
\end{tabular}

$h=$ average home advantage; $A=$ extra advantage artificial pitch; Obs. = Observations; in parentheses robust standard errors; $* * *(* *, *)$ significant at a $1 \%(5 \%, 10 \%)$ level

where $S_{i j t}=\left(w_{i j t}+w_{j i t}\right) / 2$ and $\epsilon_{i j t}=\left(\varepsilon_{i j t}+\varepsilon_{j i t}\right) / 2$.

For every pair of matches (half) the sum of the match outcomes can be used as a dependent variable in a regression such that the constant is equal to the regular home advantage.

\subsection{Parameter Estimates}

Table 4 shows the parameter estimates of equation (15). The first two columns shows the results in terms of goals per match; the third and fourth column do the same for points per match. Panel a represents the baseline estimates identical to the calculations in Table 3 showing that the regular home advantage is equal to 0.24 goals and 0.35 points, both significantly different from zero at a $1 \%$-level. The additional home advantage related to an artificial pitch is equal to 0.39 goals, significant at a $5 \%$-level and 0.32 points, insignificantly different from zero.

Panel $\mathrm{b}$ shows parameter estimates distinguishing between matches of the "classical" top-3 (Feyenoord, Ajax and PSV) and other matches. There is a difference in average home advantage between the two groups of teams although the differences are small. For example, in terms of goals, the regular home difference is 0.23 for the top- 3 and 0.35 for the other teams. The main difference is in terms of the additional home advantage because of an artificial pitch. This is substantially higher if artificial pitch teams play against the top-3 than if they play against the other teams. In terms of goals the additional home advantage because of an artificial pitch is significant when playing against the top-3 while this is not the case in terms of points. For the non-top-3 matches none of the artificial pitch effects is significantly different from zero.

Panel c shows parameter estimates distinguishing between teams that were present in every season - panel teams - and those who were not. For the panel team matches there are significant positive regular home advantages while for the nonpanel teams there are significant artificial pitch additional home advantages.

Panel d shows that for matches between non-top 3 panel team there is a clear significant positive regular home advantage but no significant additional artificial 
Table 5 Seasonal stadium attendance; clubs that played in the lower league 2014/15 to 2017/18 (1000)

\begin{tabular}{lrrrrrrrr}
\hline & $14 / 15$ & $15 / 16$ & $16 / 17$ & $17 / 18$ & Eredivisie & Lower league & $\Delta(\%)$ & AP \\
\hline SC Cambuur & 165 & 165 & $\mathbf{1 3 5}$ & $\mathbf{1 3 8}$ & 165 & $\mathbf{1 3 6}$ & 20 & 1 \\
FC Dordrecht & 66 & $\mathbf{3 5}$ & $\mathbf{2 8}$ & $\mathbf{2 9}$ & 66 & $\mathbf{3 1}$ & 115 & 1 \\
Go Ahead Eagles & 134 & $\mathbf{1 5 3}$ & 159 & $\mathbf{1 3 1}$ & 146 & $\mathbf{1 4 2}$ & 3 & 0 \\
De Graafschap & $\mathbf{9 4}$ & 184 & $\mathbf{1 6 2}$ & $\mathbf{1 5 9}$ & 184 & $\mathbf{1 3 8}$ & 33 & 0 \\
NAC Breda & 308 & $\mathbf{2 5 1}$ & $\mathbf{2 5 2}$ & 313 & 310 & $\mathbf{2 5 1}$ & 24 & 0 \\
N.E.C. & $\mathbf{1 8 1}$ & 199 & 193 & $\mathbf{1 8 3}$ & 196 & $\mathbf{1 8 2}$ & 8 & 0 \\
Roda JC & $\mathbf{2 0 4}$ & 252 & 236 & 214 & 234 & $\mathbf{2 0 4}$ & 15 & 1 \\
Sparta Rotterdam & $\mathbf{1 0 8}$ & $\mathbf{1 4 3}$ & 174 & 172 & 173 & $\mathbf{1 2 6}$ & 37 & 1 \\
VVV Venlo & $\mathbf{8 2}$ & $\mathbf{7 0}$ & $\mathbf{9 3}$ & 116 & 116 & $\mathbf{8 2}$ & 42 & 1 \\
Average & & & & & & & 33 &
\end{tabular}

Numbers in bold are from when the team played in a lower league; $\Delta(\%)$ percentage difference in attendance between Eredivisie and the lower league, $A P$ artificial pitch.

www.voetbal.com

pitch home advantage. This implies that the teams in this group with an artificial pitch-ADO Den Haag, Excelsior, Heracles Almelo, PEC Zwolle-have no additional home advantage if they play against the natural teams in this group-FC Groningen, sc Heerenveen, FC Twente, FC Utrecht, Vitesse, Willem II. In the other matches there is both a positive and significant regular home advantage of 0.17 goals and 0.25 points as well as a positive and significant additional home advantage of an artificial pitch of 0.53 goals and 0.63 points. These results indicate that especially teams with natural grass playing at the bottom of the league suffer from disadvantages when playing against teams with an artificial pitch. This suggests that the additional home advantage of playing on an artificial pitch may affect which team relegates at the end of the season. The consequences of relegation are severe. The revenues of a relegated club drop because of lower revenues from television deals, less financial support from sponsor deals and lower stadium attendance. Table 5 gives a summary overview of average stadium attendance for those teams that played in both the Eredivisie and the lower league in the four seasons of my analysis. The team with the highest attendance, NAC Breda, played two seasons in the Eredivisie and two seasons in the lower league (the so called "Eerste Divisie"). On average NAC Breda attracted 310,000 attendants in the Eredivisie and 251,000 attendants in the lower league, a difference of $24 \%$. There is a strong variation in the league effect across teams with average $33 \%$ difference in attendance between Eredivisie and the lower league.

Panel e illustrates the sensitivity of the parameter estimates from a calendar time perspective. Ignoring season 2017/18 does not change the estimated average home advantage very much but it does increase the estimated additional advantage of having an artificial pitch a lot. ${ }^{1}$ If the last season is ignored the estimated additional home advantage of an artificial pitch is 0.53 goals and 0.63 points, both significantly different from zero at a 5\%-level. In a previous version of the paper ( van Ours 2017)

\footnotetext{
1 The appendix shows that in 2016/17 all six teams with an artificial pitch have a positive home advantage while in 2017/18 three of the seven teams with an artificial pitch have a negative home advantage.
} 
I used the parameter estimates of panel e to simulate the number of points that would have been achieved in absence of the artificial pitch effects. There I find that teams playing near the bottom on natural grass have been relegated who would have otherwise stayed in the top tier. Similarly, teams playing their home matches on an artificial pitch stayed up but would have otherwise been relegated.

\section{Conclusions}

Home advantage is a phenomenon that is undisputed in professional football and not much of an issue as in all competitions teams play an equal number of home and away matches. However, from an analysis of matches in four seasons of professional football in the Netherlands, I conclude that teams who play on an artificial pitch have an additional home advantage compared to teams who play on natural grass. The question that is hard to answer with the data at hand is what is driving the additional home advantage of playing on an artificial pitch. It could be the lack of experience of the players in the team that plays its home matches on natural grass. Perhaps players who are more used to playing on an artificial pitch have a better control over the ball anticipating unexpected i.e. different movements than on natural grass. It could also be that teams with an artificial pitch attract players who are better able to perform at these pitches.

There are pros and cons to playing football on an artificial pitch. The pros are predominantly financial since the costs of introducing an artificial pitch are limited while maintenance costs are substantially lower than those of a natural grass pitch which needs fertilizer, mowing and other maintenance. The cons are that coaches and players generally do not like artificial pitches because of the supposed increased risk of injuries and the change in ball dynamics. A question that is also hard to answer is why not all teams in the lower part of the Eredivisie have an artificial pitch. After all, for clubs at the bottom of the league, there may be a trade-off between buying a good player and having an artificial pitch or having a more expensive natural grass pitch and a lower quality squad. However, it could also be that teams who play on an artificial pitch have more difficulties in attracting good players because of their fear of injuries. It could be that teams with an artificial pitch have to offer a higher salary to persuade players to sign a contract. If so, the direct financial benefits of playing on an artificial pitch are reduced by the increase in players' salaries.

Open Access This article is distributed under the terms of the Creative Commons Attribution 4.0 International License (http://creativecommons.org/licenses/by/4.0/), which permits unrestricted use, distribution, and reproduction in any medium, provided you give appropriate credit to the original author(s) and the source, provide a link to the Creative Commons license, and indicate if changes were made.

\section{Appendix: Calculated Home Advantage Per Team}

Clarke and Norman (1995) provide a straightforward method to calculate the average home advantage of a team over a season. An example of calculating the home advantage and quality of Feyenoord for season 2016/17 - for many football supporters the most exiting of the past seasons - is shown in Table 6. The ranking in this 
Table 6 Calculated home advantage and quality per team in terms of goals; four seasons

\begin{tabular}{|c|c|c|c|c|c|c|c|c|c|c|}
\hline & & $\mathrm{Hf}$ & $\mathrm{Ha}$ & HGD & Af & $\mathrm{Aa}$ & AGD & $\mathrm{h}$ & $\mathrm{q}$ & $\mathrm{AP}$ \\
\hline \multicolumn{11}{|l|}{$2014 / 15$} \\
\hline 1 & PSV & 50 & 12 & 38 & 42 & 19 & 23 & 0.59 & 1.55 & 0 \\
\hline 2 & Ajax & 37 & 11 & 26 & 32 & 18 & 14 & 0.40 & 1.06 & 0 \\
\hline 3 & $\mathrm{AZ}$ & 30 & 27 & 3 & 33 & 29 & 4 & -0.41 & 0.55 & 0 \\
\hline 4 & Vitesse & 36 & 18 & 18 & 30 & 25 & 5 & 0.47 & 0.56 & 0 \\
\hline 5 & sc Heerenveen & 33 & 21 & 12 & 20 & 25 & -5 & 0.72 & -0.01 & 0 \\
\hline 6 & Feyenoord & 31 & 20 & 11 & 25 & 19 & 6 & -0.03 & 0.64 & 0 \\
\hline 7 & PEC Zwolle & 40 & 15 & 25 & 19 & 28 & -9 & 1.78 & -0.29 & 1 \\
\hline 8 & FC Groningen & 26 & 18 & 8 & 23 & 35 & -12 & 0.90 & -0.41 & 0 \\
\hline 9 & Willem II & 25 & 22 & 3 & 21 & 28 & -7 & 0.28 & -0.10 & 0 \\
\hline 10 & FC Twente & 26 & 23 & 3 & 30 & 28 & 2 & -0.28 & 0.43 & 0 \\
\hline 11 & FC Utrecht & 32 & 31 & 1 & 28 & 31 & -3 & -0.10 & 0.15 & 0 \\
\hline 12 & SC Cambuur & 25 & 22 & 3 & 21 & 34 & -13 & 0.65 & -0.45 & 1 \\
\hline 13 & ADO Den Haag & 30 & 23 & 7 & 14 & 30 & -16 & 1.09 & -0.64 & 1 \\
\hline 14 & Heracles Almelo & 23 & 29 & -6 & 24 & 35 & -11 & -0.03 & -0.30 & 1 \\
\hline 15 & Excelsior & 26 & 37 & -11 & 21 & 26 & -5 & -0.72 & 0.07 & 1 \\
\hline 16 & NAC Breda & 19 & 32 & -13 & 17 & 36 & -19 & 0.03 & -0.75 & 0 \\
\hline 17 & Go Ahead Eagles & 14 & 29 & -15 & 15 & 30 & -15 & -0.35 & -0.51 & 0 \\
\hline 18 & FC Dordrecht & 15 & 34 & -19 & 9 & 42 & -33 & 0.53 & -1.56 & 1 \\
\hline Total & & & & 94 & & & -94 & 5.53 & 0.00 & \\
\hline Overall average & & & & 5.22 & & & -5.22 & 0.31 & 0.00 & \\
\hline Artificial pitch teams & & & & -0.17 & & & -14.50 & 0.55 & -0.53 & \\
\hline Natural grass teams & & & & 7.92 & & & -0.58 & 0.19 & 0.26 & \\
\hline \multicolumn{11}{|l|}{$2015 / 16$} \\
\hline 1 & PSV & 41 & 16 & 25 & 47 & 16 & 31 & -0.69 & 2.04 & 0 \\
\hline 2 & Ajax & 49 & 12 & 37 & 32 & 9 & 23 & 0.56 & 1.53 & 0 \\
\hline 3 & Feyenoord & 33 & 14 & 19 & 29 & 26 & 3 & 0.68 & 0.41 & 0 \\
\hline 4 & $\mathrm{AZ}$ & 38 & 24 & 14 & 32 & 29 & 3 & 0.37 & 0.43 & 0 \\
\hline 5 & Heracles Almelo & 28 & 23 & 5 & 19 & 26 & -7 & 0.43 & -0.13 & 1 \\
\hline 6 & FC Utrecht & 30 & 24 & 6 & 27 & 24 & 3 & -0.13 & 0.45 & 0 \\
\hline 7 & FC Groningen & 25 & 19 & 6 & 16 & 29 & -13 & 0.87 & -0.49 & 0 \\
\hline 8 & PEC Zwolle & 35 & 27 & 8 & 21 & 27 & -6 & 0.56 & -0.08 & 1 \\
\hline 9 & Vitesse & 30 & 18 & 12 & 25 & 20 & 5 & 0.12 & 0.55 & 0 \\
\hline 10 & N.E.C. & 25 & 17 & 8 & 12 & 25 & -13 & 1.00 & -0.50 & 0 \\
\hline 11 & ADO Den Haag & 20 & 22 & -2 & 28 & 27 & 1 & -0.50 & 0.36 & 1 \\
\hline 12 & sc Heerenveen & 24 & 29 & -5 & 22 & 32 & -10 & 0.00 & -0.27 & 0 \\
\hline 13 & FC Twente & 31 & 25 & 6 & 18 & 39 & -21 & 1.37 & -0.96 & 0 \\
\hline 14 & Roda JC & 15 & 25 & -10 & 19 & 30 & -11 & -0.25 & -0.32 & 1 \\
\hline 15 & Excelsior & 21 & 31 & -10 & 13 & 29 & -16 & 0.06 & -0.61 & 1 \\
\hline 16 & Willem II & 19 & 26 & -7 & 16 & 27 & -11 & -0.07 & -0.33 & 0 \\
\hline 17 & De Graafschap & 23 & 29 & -6 & 16 & 37 & -21 & 0.62 & -0.92 & 0 \\
\hline 18 & SC Cambuur & 12 & 32 & -20 & 21 & 47 & -26 & 0.06 & -1.17 & 1 \\
\hline
\end{tabular}


Table 6 (continued)

\begin{tabular}{|c|c|c|c|c|c|c|c|c|c|c|}
\hline & & $\mathrm{Hf}$ & $\mathrm{Ha}$ & HGD & Af & $\mathrm{Aa}$ & AGD & $\mathrm{h}$ & $\mathrm{q}$ & AP \\
\hline Total & & & & 86 & & & -86 & 5.06 & 0.00 & \\
\hline Overall average & & & & 4.78 & & & -4.78 & 0.28 & 0.00 & \\
\hline Artificial Pitch teams & & & & -4.83 & & & -10.83 & 0.06 & -0.32 & \\
\hline Natural Grass teams & & & & 9.58 & & & -1.75 & 0.39 & 0.16 & \\
\hline \multicolumn{11}{|l|}{$2016 / 17$} \\
\hline 1 & Feyenoord & 56 & 11 & 45 & 30 & 14 & 16 & 1.33 & 1.24 & 0 \\
\hline 2 & Ajax & 48 & 12 & 36 & 31 & 11 & 20 & 0.52 & 1.51 & 0 \\
\hline 3 & PSV & 35 & 9 & 26 & 33 & 14 & 19 & -0.04 & 1.48 & 0 \\
\hline 4 & FC Utrecht & 28 & 17 & 11 & 26 & 21 & 5 & -0.10 & 0.71 & 0 \\
\hline 5 & Vitesse & 31 & 21 & 10 & 20 & 19 & 1 & 0.08 & 0.48 & 0 \\
\hline 6 & $\mathrm{AZ}$ & 31 & 25 & 6 & 25 & 27 & -2 & 0.02 & 0.31 & 0 \\
\hline 7 & FC Twente & 28 & 22 & 6 & 20 & 28 & -8 & 0.40 & -0.04 & 0 \\
\hline 8 & FC Groningen & 25 & 24 & 1 & 30 & 27 & 3 & -0.60 & 0.63 & 0 \\
\hline 9 & sc Heerenveen & 26 & 16 & 10 & 28 & 37 & -9 & 0.71 & -0.11 & 0 \\
\hline 10 & Heracles Almelo & 32 & 21 & 11 & 21 & 34 & -13 & 1.02 & -0.35 & 1 \\
\hline 11 & ADO Den Haag & 22 & 21 & 1 & 15 & 38 & -23 & 1.02 & -0.91 & 1 \\
\hline 12 & Excelsior & 27 & 25 & 2 & 16 & 35 & -19 & 0.83 & -0.68 & 1 \\
\hline 13 & Willem II & 17 & 22 & -5 & 12 & 22 & -10 & -0.17 & -0.12 & 0 \\
\hline 14 & PEC Zwolle & 19 & 28 & -9 & 20 & 39 & -19 & 0.15 & -0.64 & 1 \\
\hline 15 & Sparta Rotterdam & 24 & 24 & 0 & 18 & 37 & -19 & 0.71 & -0.67 & 1 \\
\hline 16 & Roda JC & 17 & 18 & -1 & 9 & 33 & -24 & 0.96 & -0.96 & 1 \\
\hline 17 & N.E.C. & 21 & 26 & -5 & 11 & 33 & -22 & 0.58 & -0.83 & 0 \\
\hline 18 & Go Ahead Eagles & 20 & 35 & -15 & 12 & 38 & -26 & 0.21 & -1.03 & 0 \\
\hline Total & & & & 130 & & & -130 & 7.65 & 0.00 & \\
\hline Overall average & & & & 7.22 & & & -7.22 & 0.42 & 0.00 & \\
\hline Artificial Pitch teams & & & & 0.67 & & & -19.50 & 0.78 & -0.70 & \\
\hline Natural Grass teams & & & & 10.50 & & & -1.08 & 0.25 & 0.35 & \\
\hline \multicolumn{11}{|l|}{$2017 / 18$} \\
\hline 1 & PSV & 44 & 9 & 35 & 43 & 30 & 13 & 1.03 & 0.97 & 0 \\
\hline 2 & Ajax & 45 & 12 & 33 & 44 & 21 & 23 & 0.28 & 1.57 & 0 \\
\hline 3 & $\mathrm{AZ}$ & 40 & 23 & 17 & 32 & 15 & 17 & -0.35 & 1.27 & 0 \\
\hline 4 & Feyenoord & 37 & 17 & 20 & 39 & 22 & 17 & -0.16 & 1.26 & 0 \\
\hline 5 & Vitesse & 35 & 20 & 15 & 28 & 27 & 1 & 0.53 & 0.33 & 0 \\
\hline 6 & FC Utrecht & 32 & 21 & 11 & 26 & 32 & -6 & 0.72 & -0.07 & 0 \\
\hline 7 & ADO Den Haag & 26 & 27 & -1 & 19 & 26 & -7 & 0.03 & -0.08 & 1 \\
\hline 8 & sc Heerenveen & 21 & 24 & -3 & 27 & 29 & -2 & -0.41 & 0.22 & 0 \\
\hline 9 & PEC Zwolle & 27 & 20 & 7 & 15 & 34 & -19 & 1.28 & -0.82 & 1 \\
\hline 10 & Heracles Almelo & 29 & 25 & 4 & 21 & 39 & -18 & 1.03 & -0.75 & 1 \\
\hline 11 & Excelsior & 16 & 24 & -8 & 25 & 32 & -7 & -0.41 & -0.06 & 1 \\
\hline 12 & FC Groningen & 32 & 21 & 11 & 18 & 29 & -11 & 1.03 & -0.36 & 0 \\
\hline 13 & Willem II & 31 & 29 & 2 & 19 & 34 & -15 & 0.72 & -0.57 & 0 \\
\hline 14 & NAC Breda & 26 & 31 & -5 & 15 & 26 & -11 & 0.03 & -0.31 & 0 \\
\hline
\end{tabular}


Table 6 (continued)

\begin{tabular}{lllllllllll}
\hline & & Hf & Ha & HGD & Af & Aa & AGD & h & q & AP \\
\hline 15 & VVV Venlo & 19 & 29 & -10 & 16 & 25 & -9 & -0.41 & -0.17 & 1 \\
16 & Roda JC & 21 & 34 & -13 & 21 & 35 & -14 & -0.28 & -0.45 & 1 \\
17 & Sparta Rotterdam & 21 & 36 & -15 & 13 & 39 & -26 & 0.34 & -1.16 & 1 \\
18 & FC Twente & 25 & 31 & -6 & 12 & 32 & -20 & 0.53 & -0.83 & 0 \\
Total & & & & 94 & & & -94 & 5.53 & 0.00 \\
Overall average & & & & 5.22 & & & -5.22 & 0.31 & 0.00 \\
Artificial Pitch teams & & & & -5.14 & & & -14.29 & 0.23 & -0.50 \\
Natural Grass teams & & & & & & & & & &
\end{tabular}

$H f$ goals scored in home matches, $H a$ goals conceded in home matches, $H G D$ home goal difference, $A f$ goals scored in away matches, $A a$ goals conceded in away matches, $A G D$ away goal difference, $h$ home advantage, $q$ quality

table is according to the final ranking in the season. Over the season, a total of 130 more goals are scored in home games than in away games. Therefore, using equation (7): $H=\frac{130}{17}=7.65$. Then, using equation (11) for Feyenoord the home advantage is equal to $(45-16-7.65) / 16)=1.33$ and from equation (12) it follows that the quality of Feyenoord is equal to $(45-17 * 1.33) / 18=1.24$. The calculations for the others team are accordingly.

\section{References}

Andersson, H., Ekblom, B., \& Krustrup, P. (2008). Elite football on artificial turf versus natural grass: Movement patterns, technical standards, and player impressions. Journal of Sports Sciences, 26(2), $113-122$.

Barnett, V., \& Hilditch, S. (1993). The effect of an artificial pitch surface on home teamperformance in football (soccer). Journal of the Royal Statistical Society: Series A (Statistics in Society), 156(1), 39-50.

Boyko, R., Boyko, A., \& Boyko, M. (2010). Referee bias contributes to home advantage in English premiership football. Journal of Sports Sciences, 25(11), 1185-1194.

Buraimo, B., Forrest, D., \& Simmons, R. (2010). The 12th man? Refereeing bias in English and German soccer. Journal of the Royal Statistical Society: Series A (Statistics in Society), 173(2), 431-449.

Clarke, S. R., \& Norman, J. M. (1995). Home ground advantage of individual clubs in English soccer. The Statistician, 44(4), 509-521.

Ekstrand, J., Hägglund, M., \& Fuller, C. W. (2011). Comparison of injuries sustained on artificial turf and grass by male and female elite football players. Scandinavian Journal of Medicine \& Science in Sports, 21, 824-832.

Hvattum, L. M. (2015). Playing on artificial turf may be an advantage for Norwegian soccer teams. Journal of Quantitative Analysis in Sports, 11(3), 183-192.

Lanzetti, R. M., Ciompi, A., Lupariello, D., Guzzini, M., De Carli, A., \& Ferretti, A. (2017). Safety of thid-generation artificial turf in male elite professional soccer players in Italian major league. Scandinavian Journal of Medicine \& Science in Sports, 27, 435-439.

Pollard, R. (1986). Home advantage in soccer: A retrospective analysis. Journal of Sports Sciences, 4(3), 237-248.

Ponzo, M., \& Scoppa, V. (2018). Does the home advantage depend on crowd support? Evidence from same-stadium derbies. Journal of Sports Economics, 19(4), 562-582. 
Trombley, M. J. (2016). Does artificial grass affect the competitive balance in major league soccer? Journal of Sports Analytics, 2, 73-87.

van Ours, J. C. (2017). Artificial pitches and unfair home advantage in professional football. Tinbergen Institute Discussion Paper, 2017-93.

Publisher's Note Springer Nature remains neutral with regard to jurisdictional claims in published maps and institutional affiliations. 